\title{
Dissolution Stability of Cephalexin Extemporaneous Suspensions During an Accelerated Stability Study
}

\author{
Marta I. V. Brevedan, María A. Varillas, \\ and Noelia L. Gonzalez Vidal* \\ Cátedra Control de Calidad de Medicamentos, Departamento de Biología, Bioquímica y \\ Farmacia, Universidad Nacional del Sur, San Juan 670, B8000ICN Bahía Blanca, Argentina
}

\begin{abstract}
The aim of the present study was to evaluate the influence of accelerated aging conditions on drug content and in vitro dissolution stability of three cephalexin (CE) extemporaneous suspensions obtained from pharmacies and a local state laboratory. The specific gravity, $\mathrm{pH}$, and visual appearance of $\mathrm{CE}$ oral extemporaneous suspension were also studied. Dissolution profiles were performed according to FDA recommendations, since there is no official dissolution method codified. Analyses were performed throughout the administration period of the reconstituted suspension ( 7 days at room temperature storage or 14 days under refrigeration), at time zero, and during twelve months of storage of the powders under ICH accelerated aging conditions. Dissolution Efficiency $(D E)$ values and assay results were analyzed via analysis of variance (ANOVA) to evaluate the effect of aging conditions on the stability of each formulation. From a clinical point of view, the storage conditions applied did not affect dissolution or chemical stability of CE oral extemporaneous suspensions.
\end{abstract}

\section{INTRODUCTION}

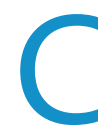

ephalexin (CE) oral suspensions are useful and effective pharmaceutical formulations for patients hypersensitive to penicillin and for patients who have difficulty swallowing solid dosage forms. Cephalosporins are active pharmaceutical ingredients used worldwide in oral formulations because of their proven track record of broad-spectrum antibacterial activity and excellent safety over more than thirty years of clinical use $(1,2)$. CE is a first-generation cephalosporin antibiotic used to treat infections of the urinary tract, respiratory tract, skin, and soft tissue (3). CE is almost completely absorbed from the gastrointestinal tract and produces a peak plasma concentration one hour after a 500-mg oral dose. Absorption may be delayed if taken with food. CE is widely distributed in the body, and its half-life is about one hour. It is not metabolized, and about $80 \%$ or more of a dose is excreted unchanged in the urine (4).

Physical stability of extemporaneous suspensions is a parameter not often considered but of crucial evaluation due to the consequences it can have on drug bioavailability. Stability studies carried out on extemporaneous products only monitor changes in chemical stability, visual appearance, $\mathrm{pH}$, caking, and redispersability, with no focus on in vitro dissolution stability (5-7).

Suspensions can be considered analogous to the disintegrated forms of tablets and capsules. If in vitro dissolution evaluation is a priority for the latter, it is logical to extend the requirement to suspensions as a limiting step to absorption and bioavailability (6-8). However, fewer than $10 \%$ of codified oral suspensions have a dissolution test described $(9,10)$, and to the best of our knowledge,

\footnotetext{
${ }^{*}$ Corresponding author.
}

among the few studies carried out on suspension dissolution, almost none of them consider changes in dissolution during the administration period of the reconstituted form (11-18). If a product is stored under the conditions specified on the label, it is expected to maintain its initial dissolution behavior throughout its life, which is known as Dissolution Stability (19). This concept is a critical biopharmaceutical parameter because of the potential impact it may have on the bioavailability of the product. Therefore, it is essential that the dissolution characteristics of a pharmaceutical formulation, whether tablet, capsule, or even suspension (5), remain unchanged throughout its shelf life.

In a previous work (20), the appropriate general conditions for performing dissolution profiles of extemporaneous suspensions were established. Our research attempted to evaluate if $\mathrm{ICH}$ accelerated storage conditions (21) also significantly affect the dissolution stability of another cephalosporin antibiotic, such as CE. The aim of the present work was to evaluate and compare the influence of these aging conditions on the drug content and in vitro dissolution stability of three different CE suspensions in the Argentinean market during the administration period and during twelve months of powder storage.

\section{MATERIALS AND METHODS \\ Reagents and Samples}

Analytical grade potassium dihydrogen phosphate and HPLC grade methanol, acetonitrile, and water (J. T. Baker, USA) were used for chromatographic determinations. Distilled water was used as dissolution medium. CE monohydrate reference standard was purchased from INAME (ANMAT, Argentina). Two CE extemporaneous oral suspensions, manufactured by different pharmaceutical compa- 
nies, were purchased from pharmacies in Argentina. A third formulation was kindly provided by a public production laboratory. They all contained $250 \mathrm{mg}$ CE per $5 \mathrm{~mL}$.

At each sampling time, extemporaneous CE suspensions were reconstituted with a given volume of tap water according to instructions on the label and mixed by a standardized procedure. All tests were performed within product expiration dates, which were similar for all formulations.

\section{Analyses Schedule}

The analyses were performed during the administration period of the reconstituted formulation at time of reconstitution (0), after 7 days of storage at room temperature (7RT), and after 14 days of storage under refrigeration (14R); throughout the powder storage period at time zero and after $3,6,9$, and 12 month ( $0 \mathrm{M}, 3 \mathrm{M}, 6 \mathrm{M}, 9 \mathrm{M}, 12 \mathrm{M})$ under $\mathrm{ICH}$ accelerated aging conditions for Argentinean climatic zone, $40^{\circ} \mathrm{C} / 75 \% \mathrm{RH}(21)$. These conditions were obtained using a stability chamber (SCT Pharma, model ICH 830 L, Argentina).

\section{Visual Inspection}

During the stability study, all formulations were visually inspected for signs of caking, color and odor changes, and redispersion problems.

\section{pH}

The $\mathrm{pH}$ of each reconstituted suspension was measured with an Altronix TPX-I pH meter at every stage of stability evaluation (10).

\section{Assay}

During the administration period throughout the storage of the powders, the effect of aging conditions on the chemical stability of CE was examined using HPLC (10). Reversed-phase HPLC was performed on a system consisting of a quaternary gradient pump (Spectra System P4000), a vacuum membrane degasser (Spectra System SCM1000), a Rheodyne injector (model 9125) with a 20- $\mu \mathrm{L}$ loop, a UVvis detector (Spectra System UV2000) set at $254 \mathrm{~nm}$, and a chromatography workstation (ChromQuest).

The mobile phase consisted of a mixture of methanol, acetonitrile, a solution of potassium dihydrogen phosphate at $13.6 \mathrm{~g} / \mathrm{L}$, and water (2:5:10:83; v/v/v/v). Fresh mobile phase was prepared daily, filtered through a $47-\mathrm{mm}$ nylon membrane $(0.45-\mu \mathrm{m}$ pore size, $\mu$ clar, Argentina), and vacuum degassed before use. Separation was performed at room temperature on a Hypersil C18 reversed-phase column (Waters), $10-\mu \mathrm{m}$ particle size, and $250 \times 4.6 \mathrm{~mm}$ i.d. The column was equilibrated for at least $45 \mathrm{~min}$ with mobile phase flowing through the chromatographic system before starting the assay. All analyses were performed under isocratic conditions at a flow rate of $1.5 \mathrm{~mL} / \mathrm{min}$.

Standard solutions were prepared on a weight basis using HPLC grade water as diluent, sonicated for $10 \mathrm{~min}$ at room temperature, and suitably diluted. An appropriate volume was filtered through a $25-\mathrm{mm}$ nylon membrane disposable filter $(0.45-\mu \mathrm{m}$ pore size, $\mu$ clar, Argentina). They were injected in triplicate (RSD $<2.0 \%$ ), and the results averaged. Sample solutions were also prepared on a weight basis using $5 \mathrm{~mL}$ of suspension from each bottle after mixing with a standardized manual procedure, and then treated as the standard solutions. Samples mimicked the usual product dose. In both cases, the theoretical concentration of CE injected was approximately $20 \mu \mathrm{g} / \mathrm{mL}$, and all solutions were used on the day prepared.

The assay results were compared using ANOVA to evaluate the effect of aging conditions on the chemical stability of $C E$ in oral suspensions.

\section{Dissolution Stability Study}

Dissolution studies were performed according to FDA recommendations (22) because there is no codified method for dissolution of $C E$ extemporaneous suspension $(9,10)$.

A suspension sample equivalent to a typical dose (5 $\mathrm{mL}$ ) was taken on a weight basis using a suitable syringe-cannula system and quantitatively transferred to the dissolution vessel midway between the surface of the dissolution medium and the top of the rotating blade. Before sampling, the reconstituted suspension was mixed by manual agitation (20 upendings in $90 \mathrm{sec}$ ). To calculate the exact weight of suspension added to the vessel, syringe and cannula were weighed at three stages: empty, filled with the suspension, and after the sample was expelled into the dissolution vessel. The specific gravity of each formulation was determined to express the percentage of drug dissolved in the sampled volume $(250 \mathrm{mg} / 5 \mathrm{~mL})$.

Dissolution testing was carried out on a suitably calibrated USP Apparatus 2 (Erweka DT60) at $25 \pm 1$ rpm, under sink conditions, in $900 \mathrm{~mL}$ of deaerated distilled water at $37 \pm 0.5^{\circ} \mathrm{C}$. Samples $(10 \mathrm{~mL})$ were withdrawn at $2,5,10,20$, and $30 \mathrm{~min}$, with replacement of the same volume of fresh medium after each withdrawal, and filtered through a $25-\mathrm{mm}$ nylon membrane disposable filter $(0.45-\mu \mathrm{m}$ pore size, $\mu$ clar, Argentina). Samples were suitably diluted with HPLC grade water and analyzed using assay methodology. The concentration of each sample was calculated from a CE standard calibration curve. Results were averaged, and cumulative drug release percentages were calculated for dissolution profile estimation.

Dissolution profiles were compared using statistical evaluation of dissolution efficiency (DE). DE was calculated as the area under the dissolution curve at $30 \mathrm{~min}$ (measured using the trapezoidal rule) and expressed as percentage of the area of the rectangle described by $100 \%$ dissolution in the same time (23). DE values were compared by ANOVA to evaluate the effect of aging conditions on dissolution stability within each formulation. 
Table 1. Reconstituted Suspension HPLC Assay, pH, and Specific Gravity throughout the Accelerated Stability Study

\begin{tabular}{|c|c|c|c|c|c|c|c|}
\hline \multirow[b]{2}{*}{ Storage $^{a}$} & \multirow[b]{2}{*}{ Time $^{b}$} & \multicolumn{3}{|c|}{ Sample B } & \multicolumn{3}{|c|}{ Sample C } \\
\hline & & $\%$ assayc $^{c} \pm$ SD & pH & Specific Gravity & $\%$ assayc \pm SD & pH & Specific Gravity \\
\hline \multirow{4}{*}{$0 \mathrm{M}$} & ORT & $109.1 \pm 2.4$ & 6.3 & 1.103 & $105.5 \pm 0.3$ & 5.8 & 1.214 \\
\hline & 7RT & $96.5 \pm 2.4$ & 5.9 & 1.049 & $99.5 \pm 1.5^{*}$ & 5.5 & 1.246 \\
\hline & OR & $100.0 \pm 0.7$ & 6.3 & 1.076 & $104.0 \pm 0.2$ & 5.8 & 1.210 \\
\hline & $14 \mathrm{R}$ & $93.7 \pm 2.7$ & 6.1 & 1.028 & $97.2 \pm 0.4^{*}$ & 5.6 & 1.211 \\
\hline \multirow{4}{*}{$3 \mathrm{M}$} & ORT & $114.5 \pm 3.8$ & 6.3 & 1.085 & $97.0 \pm 0.4$ & 5.7 & 1.119 \\
\hline & 7RT & $104.6 \pm 3.9$ & 5.9 & 1.094 & $100.5 \pm 0.6^{*}$ & 5.4 & 1.198 \\
\hline & $\mathrm{OR}$ & $110.3 \pm 0.1$ & 6.2 & 1.087 & $106.3 \pm 1.4$ & 5.7 & 1.227 \\
\hline & $14 \mathrm{R}$ & $104.1 \pm 4.8$ & 6.1 & 1.084 & $105.5 \pm 1.0$ & 5.6 & 1.234 \\
\hline \multirow{4}{*}{$6 \mathrm{M}$} & ORT & $113.9 \pm 0.6$ & 5.2 & 1.109 & $107.6 \pm 1.0$ & 5.3 & 1.238 \\
\hline & 7RT & $106.2 \pm 1.5^{*}$ & 5.8 & 1.090 & $110.0 \pm 3.0$ & 5.5 & 1.223 \\
\hline & $\mathrm{OR}$ & $115.7 \pm 5.6$ & 5.6 & 1.107 & $110.9 \pm 0.6$ & 5.3 & 1.255 \\
\hline & $14 \mathrm{R}$ & $108.3 \pm 1.4$ & 6.0 & 1.087 & $110.1 \pm 0.2$ & 5.4 & 1.233 \\
\hline \multirow{4}{*}{$9 M$} & ORT & $110.3 \pm 4.7$ & 6.3 & 1.068 & $110.0 \pm 1.5$ & 5.5 & 1.223 \\
\hline & 7RT & $101.9 \pm 0.4$ & 6.1 & 1.086 & $100.3 \pm 0.8^{*}$ & 5.3 & 1.220 \\
\hline & $\mathrm{OR}$ & $110.0 \pm 5.6$ & 6.1 & 1.080 & $106.2 \pm 2.2$ & 5.4 & 1.211 \\
\hline & $14 \mathrm{R}$ & $102.1 \pm 0.9$ & 6.1 & 1.060 & $106.7 \pm 1.2$ & 5.5 & 1.229 \\
\hline \multirow{4}{*}{$12 \mathrm{M}$} & ORT & $100.1 \pm 1.9$ & 6.2 & 1.084 & $96.8 \pm 2.2$ & 5.3 & 1.232 \\
\hline & 7RT & $100.3 \pm 0.9$ & 6.1 & 1.078 & $91.9 \pm 1.1$ & 5.3 & 1.209 \\
\hline & $\mathrm{OR}$ & $97.1 \pm 0.5$ & 6.1 & 1.080 & $106.0 \pm 3.3$ & 5.4 & 1.237 \\
\hline & $14 \mathrm{R}$ & $112.7 \pm 0.8^{*}$ & 5.9 & 1.079 & $108.5 \pm 3.1$ & 5.3 & 1.223 \\
\hline
\end{tabular}

a Months of storage of powder for oral suspension under accelerated aging conditions

OM: Beginning of storage time

3M: After three months of storage

6M: After six months of storage

9M: After nine months of storage

12M: After twelve months of storage

${ }^{b}$ Stages of analysis of reconstituted forms

ORT: Immediately after reconstitution (formulation to be stored at room temperature)

OR: Immediately after reconstitution (formulation to be stored under refrigeration)

7RT: Expiration date at room temperature storage

14R: Expiration date under refrigeration

c Percent of label claim

* Significant differences ( $p$-values between 0.01 and 0.05)

\section{RESULTS AND DISCUSSION}

The recorded assay results for formulation $A$ at time zero were within the acceptance range, and a rapid dissolution with high values of $D E$ was seen. The specific gravity values were between 1.137 and 1.159, and the lowest $\mathrm{pH}$ values were recorded for this formulation (range 4.34-4.50). After three months of storage under accelerated aging conditions, the study of this formulation was discontinued because of major changes in appearance (Figure 1). Microbiological tests were performed for this pharmaceutical form, without positive results. Chemical interaction tests are now being carried out using thermal analysis.

$\mathrm{HPLC}$ assay results and values for $\mathrm{pH}$ and specific gravity throughout the accelerated aging study of formulations
$\mathrm{B}$ and $\mathrm{C}$ are recorded in Table 1. All $\mathrm{pH}$ values for formulation $\mathrm{C}$ remained in the range of 3.0-6.0, satisfying pharmacopeial specifications (10). However, $\mathrm{pH}$ values for formulation $\mathrm{B}$ were slightly higher than the upper specification limit in almost all cases. No important changes in $\mathrm{pH}$ and specific gravity values were recorded throughout the stability study. During aging of constituted suspensions, color changes and an unpleasant odor were observed, but there were no visual signs of caking, and all formulations were easily redispersed even after twelve months of storage of the powders.

CE chemical stability was evaluated by HPLC analysis. The decrease in the CE peak area and the appearance of new peaks were monitored in each run for all 


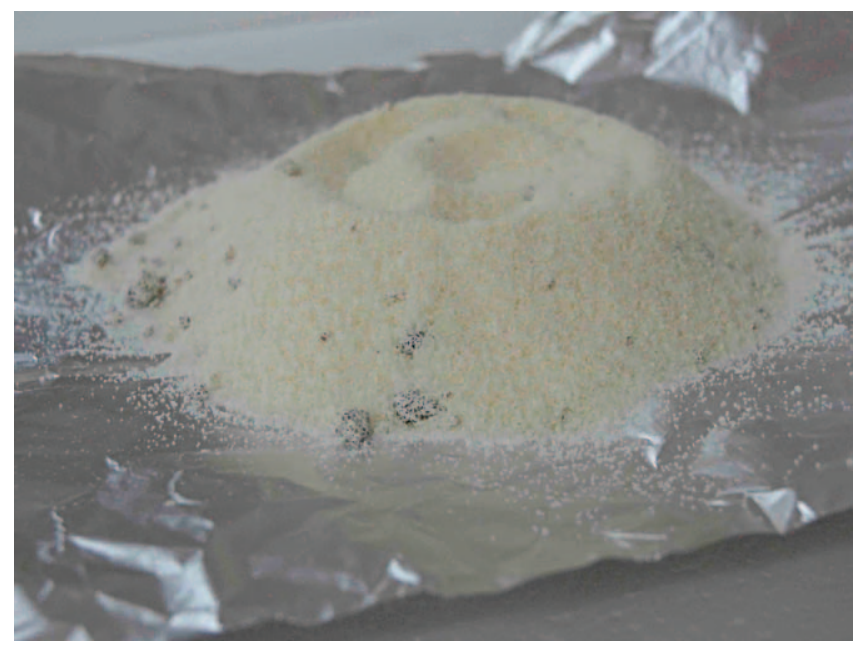

Figure 1. Appearance of sample A after three months of storage under accelerated aging conditions.

tested tablets, but only the CE peak area was quantified. Chemical stability of CE in the stressed formulations was examined against a CE reference standard, which was run simultaneously each time samples were evaluated. The CE concentration measured in the assay of each formulation remained within $90 \%$ of the labeled amount throughout the stability study (Table 1). ANOVA was used to establish differences among the assay average results during the storage period. Statistically significant differences were only recorded in few cases (two for formulation B and four for formulation C). All of these results indicate that the analyzed powders, as well as the reconstituted forms, are chemically stable during the administration period at room temperature and under refrigeration, according to pharmacopoeial specifications (10).

Both formulations showed a high dissolution rate with large percentages of drug release at early time points of the dissolution profile. In all cases, more than $70 \%$ was dissolved in 2 min for both formulations, and dissolution levels greater than $100 \%$ were achieved in most cases. Dissolution profiles were compared in terms of $D E$. Almost all $D E$ values were more than $100 \%$, which indicates an excellent dissolution performance. Variability associated with $D E$ in terms of standard deviation was less than $5 \%$ in almost all cases, with three values in the range $5-10 \%$ and only one result higher than $10 \%$ (OR, 12M, formulation $\mathrm{B}$ ). ANOVA was used to compare $D E$ values (dissolution stability). Statistical comparison of $D E$ values showed differences during the administration period of the suspension stored under room temperature or refrigeration in only in a few cases (Figure 2).

\section{CONCLUSIONS}

$\mathrm{CE}$ concentrations in formulations $\mathrm{B}$ and $\mathrm{C}$ remained within $90 \%$ of labeled amount throughout the stability

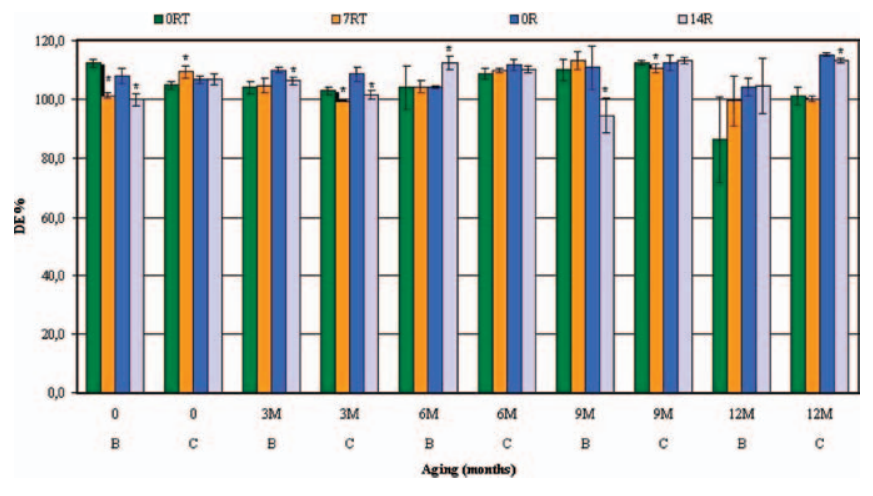

Figure 2. Dissolution efficiency (DE) evolution throughout the administration period of the reconstituted forms and powder aging (under accelerated aging conditions).

\section{* Significant changes}

ORT: Immediately after reconstitution (formulation designated for storage at room temperature)

OR: Immediately after reconstitution (formulation designated for storage under refrigeration)

7RT: Expiration date at room temperature storage

14R: Expiration date under refrigeration

$0: \quad$ Beginning of storage time

3M: After three months of storage

6M: After six months of storage

9M: After nine months of storage

12M: After twelve months of storage

study. No significant changes in $\mathrm{pH}$, specific gravity, or redispersion of the formulations were recorded. However, important changes in odor and color were found. Both formulations showed a high dissolution rate with high dissolved percentages at early time points of the dissolution profile. Although some statistical differences were found among $D E$ values throughout administration period, they do not have important clinical significance.

Throughout the product aging study, the reconstituted forms $B$ and $C$ were chemically stable and had acceptable dissolution stability during the administration period. Formulation A was not stable after three months of storage under accelerated aging conditions, and it was removed from the study. Possible interactions between drug and excipients are being analyzed.

Accelerated aging conditions do not affect the dissolution stability of all cephalosporin antibiotic suspensions in the same way. The instability shown for cefadroxil extemporaneous oral suspensions (20) was not seen in CE formulations, which were chemically and physically stable after a year of storage under these conditions.

\section{ACKNOWLEDGMENTS}

The authors thank the public production laboratory for formulation donation. This work was supported by funds from Universidad Nacional del Sur, Argentina (Project number: PGI 24/B139). 


\section{REFERENCES}

1. Schwaber, M. J.; Graham, C. S.; Sands, B. E.; Gold, H. S.; Carmeli, Y. Treatment with a broad-spectrum cephalosporin versus piperacillin-tazobactam and the risk for isolation of broad-spectrum cephalosporin-resistant Enterobacter species. Antimicrob. Agents Chemother. 2003, 47 (6), 1882-1886.

2. Gringauz, A. Introduction to Medicinal Chemistry; WileyVCH, Inc.: New York, 1997.

3. Swarbrick, J. Encyclopedia of Pharmaceutical Technology, 3rd ed.; Informa Healthcare: New York, 2007.

4. Parfitte, K., Ed. Martindale: The Complete Drug Reference, 32nd ed.; Pharmaceutical Press: London, 1999.

5. Standing, J. F.; Tuleu, C. Paediatric formulation-getting to the heart of the problem. Int. J. Pharm. 2005, $300(1-2), 56-66$.

6. Nahata, M. C.; Jackson, D. S. Stability of cefadroxil in reconstituted suspension under refrigeration and at room temperature. Am. J. Hosp. Pharm. 1991, 48 (5), 992-993.

7. Boonme, P.; Phadoongsombut, N.; Phoomborplub, P.; Viriyasom, S. Stability of extemporaneous norfloxacin suspension. Drug Dev. Ind. Pharm. 2000, 26 (7), 777-779.

8. Guideline for Submitting Documentation for the Stability of Human Drugs and Biologics; Guidance for Industry; U.S. Department of Health and Human Services, Food and Drug Administration, Center for Drug Evaluation and Research (CDER), U.S. Government Printing Office: Washington, DC, 1987; p 15.

9. The United States Pharmacopeia and National Formulary USP 30-NF 25, Spanish Ed.; The United States Pharmacopeial Convention, Inc.: Rockville, MD, 2007.

10. British Pharmacopoeia 2009; The Stationary Office: London, 2009.

11. Cárdenas, R. H. L.; Cortés, A. A. R.; Argotte, R. R.; Luna, M. P.; Dominguez, R. A. Investigation of dissolution profiles from suspensions containing benzoyl metronidazole using a statistical model with repeated measurements. Drug Dev. Ind. Pharm. 1994, 20 (6), 1063-1073.

12. Howard, S. A.; Mauger, J. W.; Phusanti, L. Dissolution profiles for multisized prednisolone acetate suspensions. J. Pharm. Sci. 1977, 66 (4), 557-559.
13. Strum, J. D.; Colaizzi, J. L.; Goehl, T. J.; Jaffe, J. M.; Pitlick, W. H.; Shah, V. P.; Poust, R. I. Bioavailability of sulfonamide suspensions I: Dissolution profiles of sulfamethizole using paddle method. J. Pharm. Sci. 1978, 67 (10), 1399-1402.

14. Mathur, L. K.; Jaffe, J. M.; Poust, R. I.; Barry, H. 3rd; Goehl, T. J.; Shah, V. P.; Colaizzi, J. L. Bioavailability and dissolution behavior of trisulfapyrimidine suspensions. J. Pharm. Sci. 1979, 68 (6), 699-702.

15. Meshali, M.; El-Sabbagh, H.; Ghanem, A.; Foda, A. Simultaneous in vitro and in vivo evaluation of both trimethoprim and sulfamethoxazole from certain dosage forms. Pharmazie 1983, 38 (6), 403-406.

16. Ezzedeen, F. W.; Majeed, S. H.; Shihab, F. A.; Mahmoud, M. J.; Robinson, D. H.; Tahseen, Y. H.; Stohs, S. J. In vitro and in vivo evaluation of four cotrimoxazole oral suspensions. Int. J. Pharm. 1990, 59 (3), 255-261.

17. Boonme, P.; Phadoongsombut, N.; Ingkatawornwong, S.; Faroongsarng, D. The formulation development and stability study of Norfloxacin suspension. Thammasat Int. J. Sc. Tech. 2002, 7 (1), 1-4.

18. Danckwerts, M. P.; Ebrahim, S.; Pillay, V. Pharmaceutical formulation of a fixed-dose anti-tuberculosis combination. Int. J. Tuberc. Lung Dis. 2003, 7 (3), 289-297.

19. Murthy, K. S.; Ghebre-Sellassie, J. Current perspectives on the dissolution stability of solid oral dosage forms. J. Pharm. Sci. 1993, 82 (2), 113-126.

20. Gonzalez Vidal, N.; Zubata, P.; Simionato, L.; Pizzorno, M. T. Dissolution Stability Study of Cefadroxil Extemporaneous Suspensions. Dissolution Technol. 2008, 15 (3), 29-36.

21. International Conference on Harmonization. Stability Testing of New Drug Substances and Products, Q1A(R2); ICH Harmonized Tripartite Guideline; Geneva, Switzerland, 2003. http://www.ich.org/fileadmin/ Public_Web_Site/ICH_Products/Guidelines/Quality/ Q1A_R2/Step4/Q1A_R2_Guideline.pdf (accessed June 21, 2011).

22. Dissolution Methods Database. U.S. Food and Drug Administration Web site. http://www.accessdata.fda. gov/scripts/cder/dissolution/dsp_SearchResults_ Dissolutions.cfm?PrintAll=1 (accessed June 21, 2012).

23. Khan, K. A. The concept of dissolution efficiency. J. Pharm. Pharmacol. 1975, 27 (1), 48-49. 